\title{
Parking Demand Prediction Method of Urban Commercial-Office Complex Buildings Based on the MRA-BAS-BP Algorithm
}

\author{
Xiang Tang $\mathbb{D}^{1},{ }^{1}$ Jianxiao Ma $\mathbb{D},{ }^{1}$ Shun Zhou $\mathbb{D}^{2},{ }^{2}$ and Tianci Shan $\mathbb{D}^{2}$ \\ ${ }^{1}$ College of Automobile and Traffic Engineering, Nanjing Forestry University, Nanjing, Jiangsu, China \\ ${ }^{2}$ Nanjing Institute of City \& Transport Planning Co., Ltd., Nanjing, Jiangsu, China \\ Correspondence should be addressed to Jianxiao Ma; xcbx@njfu.edu.cn
}

Received 10 December 2021; Accepted 6 January 2022; Published 27 February 2022

Academic Editor: Qizhou $\mathrm{Hu}$

Copyright (c) 2022 Xiang Tang et al. This is an open access article distributed under the Creative Commons Attribution License, which permits unrestricted use, distribution, and reproduction in any medium, provided the original work is properly cited.

With the increasingly significant trend of developing urban land for mixed-use, an increasing number of urban commercial and office complexes have been built. The parking demand characteristics of such buildings are more complex than the parking demand characteristics of single-use buildings due to more diverse influencing factors. As there are complicated linear and nonlinear relationships between parking demand and influencing factors, it is difficult to accurately predict parking demand using a single multiple regression analysis (MRA) model. Hence, in this paper, a combined algorithm based on the MRA model, beetle antennae search (BAS) algorithm, and BP neural network is proposed for demand prediction. In this paper, a two-level and tencategory index system is established and then mixed with the BP algorithm through the MRA model to improve the overall robustness and accuracy of the algorithm. Then, the BAS algorithm is used to search for optimal parameters involved in the BP neural network to avoid local optimization and improve the accuracy and efficiency of prediction. Finally, an instance analysis is carried out for verification, and the result indicates that the parking demand prediction accuracy of the MRA-BAS-BP algorithm is higher than the prediction accuracy of the traditional algorithm.

\section{Introduction}

In recent years, urban motorization has made a great process in China. The contradiction between growing parking demands and insufficient parking spots in buildings has become increasingly prominent. Therefore, many cities begin to pay more and more attention to the formulation of parking spaces allocated for new buildings. At present, the research on parking allocation indicators mostly focuses on the parking demand model of single business type; when it comes to urban complexes with mixed commercial and office business types, they mostly adopt the simple mode of classified demand superposition and do not fully consider the sharing benefits brought by parking peak staggering, which not only increases the cost of urban development and operation but also restricts the intensity of land compound development. With the increasing number of urban commercial complex buildings, it is of great practical significance to carry out the research on parking demand prediction of a commercial complex.
Scholars at home and abroad mostly use parking generation rate models, multiple regression analysis, vehicle origin-destination (OD) analysis, and other methods to predict parking demand for buildings. Based on influencing factors such as road network service level, Cheng et al. [1] used a multiple linear regression model to predict the parking demand for urban central culture districts (CCDs). They found that the model avoided the road network capacity saturation caused by parking and was practical, but there was approximately a $10 \%$ error between the predicted results and reality. Yu et al. [2] compared and analyzed three conventional parking demand prediction models, namely, the parking generation rate model, multiple regression model, and vehicle OD method, and found that the multiple regression model can be used in parking demand prediction for buildings with a comprehensive influence factor system and obvious linear characteristics of parking demand. However, the model has a poor parking demand prediction for buildings with some nonlinear characteristics. 
Meanwhile, some scholars have begun to apply machine learning algorithms to building parking demand prediction. Liu et al. [3] explored a spatiotemporal deep learning neural network for shared parking demand prediction and predicted the parking demand through three models: CNN, Conv-LSTM, and LSTM. The results showed that the parking demand predicted by the deep learning neural network is greatly improved in comparison with the parking demand predicted by conventional basic models. Based on the analysis of passenger travel behaviors, Gai et al. [4] proposed a parking demand prediction model with long short-term memory (LSTM) as the core to predict the parking demand of parking lots in railway stations. The results showed that the LSTM model achieves a better prediction effect than the traditional models.

Throughout research on parking demand prediction methods for existing urban commercial-office complexes at home and abroad, the parking demand of commercial-office complexes and its influencing factors can be found to show a complex linear and nonlinear relationship [5]. Among these factors, some studies use only the multiple regression analysis (MRA) method to fit and predict the linear relationship between parking demand and its influencing factors, which leads to a certain deviation in the predicted outcomes, mainly because a single multiple linear regression method cannot fit the nonlinear part of parking demand. Therefore, referring to relevant research and to compensate for the shortcomings of the MRA model, the authors in this paper combine the MRA model with a machine learning algorithm to construct a combinational algorithm with a more significant fitting effect for parking demand prediction of urban commercial-office complexes.

\section{Parking Demand Prediction Algorithm for the Urban Commercial-Office Complex}

2.1. Parameter Setting and definition. For a given commercial-office complex $i$, let $P_{i}$ denote its parking demand, $P_{\text {MRA }}(i)$ denote the predicted parking demand after MRA analysis, and $P_{o}(i)$ be the predicted parking demand after MRA-BAS-BP calculation.

The parking demand prediction algorithm proposed in this paper involves two stages: regression analysis of the parking demand for urban commercial-office complexes based on MRA and parking demand residual prediction and feedback based on BAS-BP. The variables and parameters in this algorithm are defined as follows:

(1) $\varepsilon(i)$ : the residual between the predicted parking demand value and the real value after MRA analysis

(2) $\zeta(i)$ : the MRA residual predicted by the BAS-BP algorithm

(3) $A_{j}$ : the coefficient of the $j$-th influence factor of the MRA model, and $A_{0}$ is a constant term

(4) $k$ : the spatial dimension of the BAS search and the total number of undetermined initial weights and thresholds of the BP neural network
(5) $\vec{b}$ : the moving direction of the longhorn beetle whose determination is the process of normalizing a $k$-dimensional random vector

(6) $d_{0}$ : the distance between two antennae of the longhorn beetle

(7) $x_{l s}, x_{r s}$ : the spatial coordinates of the positions of the left and right antennae of the longhorn beetle, respectively

(8) fit: the fitness function of the BAS algorithm; in this paper, the root mean squared error of the training set is used, fit $=\sum_{i=1}^{n}\left(\varepsilon_{i}-\zeta_{i}\right)^{2} / N$

(9) eta: the step length factor in BAS algorithm

(10) $d_{0}$ : the distance between the left and right antennae

(11) $\rho$ : the search accuracy of the BAS algorithm

(12) iter: the iteration ordinal number of BAS algorithm

(13) Step: the step length of each iteration of the longhorn beetle

(14) $x^{s}(s=0,1,2 \cdots, n)$ : the position of the longhorn beetle in the $s$-th iteration; $x^{0}$ is the initial position of the longhorn beetle; and $x_{\text {best }}^{s}$ is the position of the longhorn beetle with the best fit

(15) Parameters $(T, \theta)$ : the individual position of the longhorn beetle, where $T$ is the initial value of the $\mathrm{BP}$ algorithm and $\theta$ is the threshold of the BP algorithm

(16) $m$ : the number of neurons in the input layer of the BP neural network

(17) $n$ : the number of neurons in the output layer of the BP neural network

(18) $L$ : the number of neurons in the hidden layer, calculated by $L=\sqrt{m+n}+\delta$, in which $\delta$ is an integer ranging from 1 to 10

(19) $\eta$ : the learning rate, generally from 0.01 to 0.1

(20) $f$ : activation function, and sigmoid function $f(x)=$ $1 / 1+\exp (-x)$ is used in this paper

2.2. Overall Research Ideas. In this paper, we propose a twostage parking demand prediction method and study the linear and nonlinear relationships between parking demand and influencing factors in two stages. In the first stage, the author carries out MRA model prediction and calculates the residuals based on the linear relationship between the calibrated influencing factors and parking demand. In the second stage, based on the MRA model, the author uses the good nonlinear approximation ability of the BP neural network to fit and predict the nonlinear part of the algorithm, constructs the nonlinear relationship between residuals and influencing factors, and then compensates and modifies the multiple regression analysis model to compensate for the shortcomings of the linear model to improve the accuracy of parking demand prediction. The overall process is shown in Figure 1. 


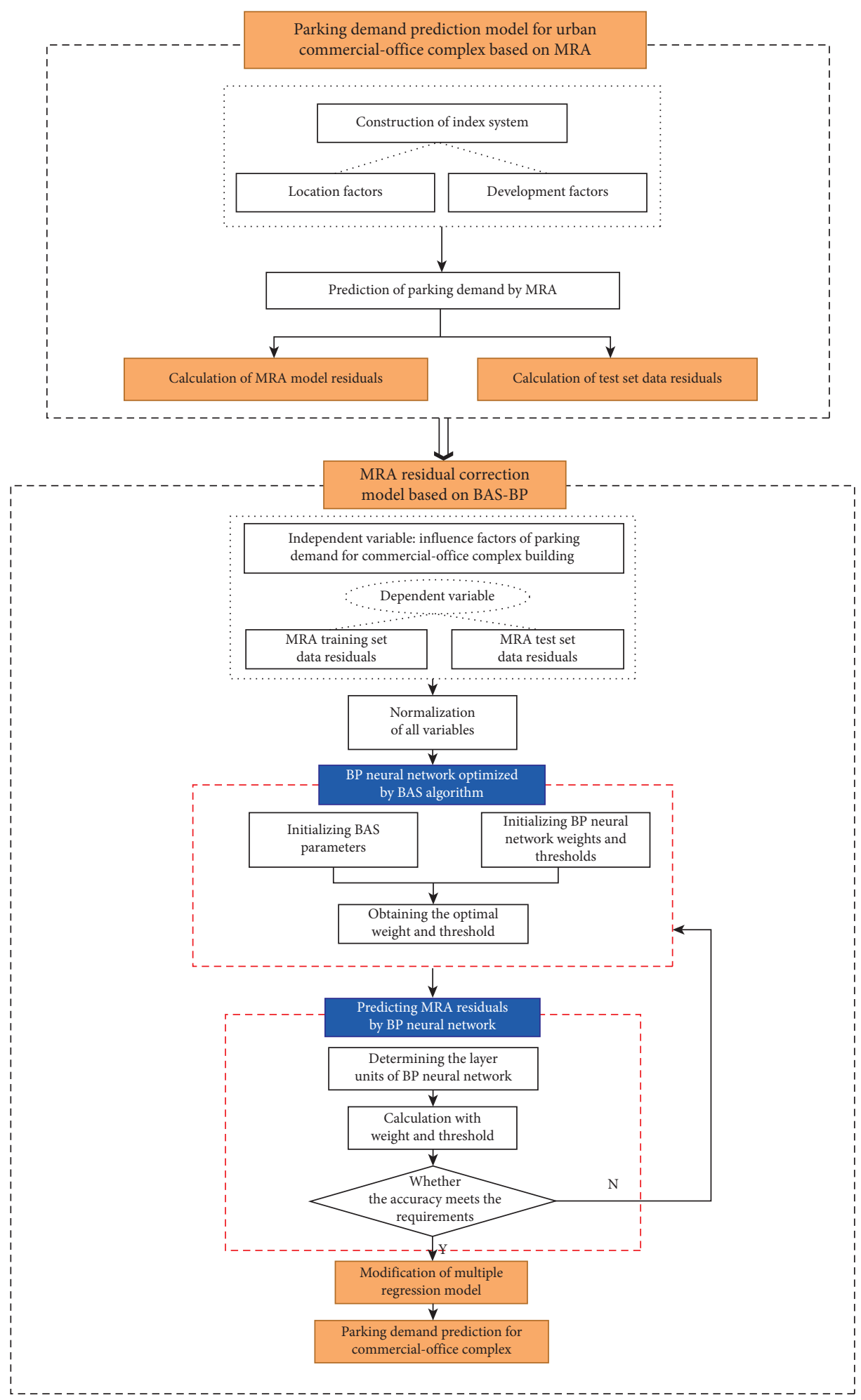

Figure 1: Flow chart of MRA-BAS-BP algorithm.

\subsection{Introduction of the Index System}

2.3.1. Construction of the Index System. Referring to the existing research literature [6] and the actual operation of the parking facilities of the commercial-office complex buildings and based on the principles of comprehensiveness, scientificity, and measurability, this research constructs a two-level and ten-category parking demand influence factor index system from two aspects of building location factors and building development factors, as shown in Table 1. 
TABLE 1: Construction of the parking demand prediction index system.

\begin{tabular}{|c|c|c|c|}
\hline Influence factors & Composition indices & Symbols & Specific meaning and calibration method \\
\hline \multirow{5}{*}{$\begin{array}{l}\text { Building location } \\
\text { factors }\end{array}$} & Proportion of car trips & $x_{1}$ & $\begin{array}{c}\text { The proportion of small- and medium-sized car trips in the total traffic } \\
\text { volume generated by buildings }\end{array}$ \\
\hline & $\begin{array}{l}\text { Car ownership rate per } \\
1,000 \text { people }\end{array}$ & $x_{2}$ & $\begin{array}{l}\text { The average number of cars per } 1,000 \text { people in the subdistrict where the } \\
\text { building is located, unit: vehicle/1,000 people }\end{array}$ \\
\hline & Location index & $x_{3}$ & $\begin{array}{l}\text { The location index is measured by the real GDP per capita }(\overline{G D P}) \text { in the } \\
\text { subdistrict where the building is located, unit: yuan/person }\end{array}$ \\
\hline & Road network capacity & $x_{4}$ & $\begin{array}{l}\text { The standard vehicle equivalent that can be accommodated by the road } \\
\text { network within the enclosed area of the first trunk road around the building } \\
\text { in peak hours, unit: } \mathrm{pcu} / \mathrm{h}\end{array}$ \\
\hline & Transit accessibility & $x_{5}$ & $\begin{array}{l}\text { An indicator to measure the convenience of people from a building to } \\
\text { complete a trip through public transportation }\end{array}$ \\
\hline \multirow{5}{*}{$\begin{array}{l}\text { Building } \\
\text { development factors }\end{array}$} & $\begin{array}{l}\text { Commercial area of the } \\
\text { building }\end{array}$ & $x_{6}$ & e commercial part of the building, unit: $\mathrm{m}^{2}$ \\
\hline & $\begin{array}{l}\text { Number of posts per } \\
\text { building }\end{array}$ & $x_{7}$ & $\begin{array}{c}\text { Maximum number of posts that can be provided in the office area of the } \\
\text { building, unit: person }\end{array}$ \\
\hline & $\begin{array}{l}\text { Parking charging } \\
\text { standard }\end{array}$ & $x_{8}$ & Price of hourly parking charge for the building, unit: yuan $/ \mathrm{h}$ \\
\hline & $\begin{array}{l}\text { Number of shared } \\
\text { parking spots }\end{array}$ & $x_{9}$ & $\begin{array}{l}\text { Number of berths provided by the building of common use for travelers with } \\
\text { commercial and office purposes, unit: PCs }\end{array}$ \\
\hline & $\begin{array}{l}\text { Building development } \\
\text { intensity }\end{array}$ & $x_{10}$ & $\begin{array}{l}\text { The building floor area ratio is used to measure the development intensity of } \\
\text { the building, which refers to the ratio of the total building area on the } \\
\text { building ground to the net land area }\end{array}$ \\
\hline
\end{tabular}

2.3.2. Acquisition and Calibration of the Index Data. Among the above indices, all indicators can be obtained through building parking survey or local statistical data, the acquisition and calculation methods are as follows:

(1) $x_{1}$ : The proportion of car trips can be obtained by issuing a questionnaire to investigate the actual operation of the object's buildings.

(2) $x_{2}$ : The car ownership rate per 1,000 people can be obtained through the traffic management department, and the population data can be obtained from the statistical department at the same time.

(3) $x_{3}$ : The location index can be obtained according to the GDP statistical data of the subdistrict.

(4) $x_{4}$ : By referring to the literature, the time-space consumption method and road network service level method can be used to calculate the road network capacity. The time-space occupancy method proposed by Louis Marchan [7] is the most widely adopted method that can be used to calculate the capacity of various road networks. Its calculation method is shown in the following equation, and the parameters involved are obtained through the actual survey:

$C=\frac{S . T}{\overline{C_{\text {car }}}}=\frac{60 \times S_{\text {road }} \times \alpha \times R_{1} \times R_{2} \times R_{3} \times R_{4} \times R_{5} \times q}{1000 \times d \times D}$,

where $S_{\text {Road }}$ is the total area (unit: $\mathrm{m}^{2}$ ) of the road, $d$ is the transverse width required for the speed movement of the vehicle to reach the capacity state (unit: $\mathrm{m}$ ), $D$ is the average travel distance during peak hours (unit: $\mathrm{m}$ ), and $q$ is the capacity of each road when the road network reaches the capacity (unit: vehicle/h). Other parameters are various correction factors, whose values are shown in Table 2.

(5) $x_{5}$ : Huanmei Qin proposed that the time in the car, walking time, waiting time, and other factors should be considered in the calculation of transit accessibility [8]. Its specific calculation process is shown in the following equation, and the parameters involved can be obtained through the survey of building parking characteristics:

$$
\begin{aligned}
P A^{※} & =\frac{30}{T_{i}^{\text {walk }}+T_{i}^{\text {wait }}}+\frac{1}{2} \sum \frac{30}{T_{j}^{\text {walk }}+T_{j}^{\text {wait }}}, \\
T^{\text {walk }} & =\frac{L^{\text {walk }}}{V^{\text {walk }}} \\
T^{\text {wait }} & =\frac{1}{2} * \frac{60}{\alpha}+k, \\
P A & =\sum P A^{※},
\end{aligned}
$$

where $T_{i}^{\text {walk }}$ is the walking time of the optimal route $i$; $T_{i}^{\text {wait }}$ is the waiting time of the optimal route $i$; $T_{j}^{\text {walk }}$ is the walking time of another route $j ; T_{j}^{\text {wait }}$ is the waiting time of another route $j$, unit: $\min ; P A ※$ is the transit accessibility index value of a certain public transport mode; $P A$ is the sum of transit accessibility index values of all public transport modes, indicating the transit accessibility index value of the building; $L_{\text {walk }}$ is the distance from the building to the bus stop (unit: $\mathrm{m}$ ); $V_{\text {walk }}$ is the 
TABLE 2: Values of correction coefficients of the time-space consumption method.

\begin{tabular}{lcccccc}
\hline Reduction factor & $\alpha$ & $R_{1}$ & $R_{2}$ & $R_{3}$ & $R_{4}$ \\
\hline Value range & $0.4-0.5$ & $0.75-0.8$ & $0.9-0.95$ & $0.7-0.8$ & $0.7-0.85$ & $0.7-0.85$ \\
\hline
\end{tabular}

average walking speed of pedestrians (taking $50 \mathrm{~m} /$ $\min ) ; k$ is the reliability coefficient of bus stops, 1 for rail traffic and 2 for bus; and $\alpha$ is the bus arrival rate (unit: vehicle/h).

(6) $x_{6}$ : The commercial area of the building can be obtained by building design plan.

(7) $x_{7}$ : The number of posts in the building can be obtained by the survey of parking facilities.

(8) $x_{8}$ : The parking charging standard can be obtained by the survey of parking facilities.

(9) $x_{9}$ : The number of shared parking spots can be obtained by the survey of parking facilities.

(10) $x_{10}$ : The building development intensity can be acquired from the survey of parking facilities and parking characteristics in the building.

\subsection{Phase I: Parking Demand Prediction Algorithm Based on the MRA Model}

2.4.1. MRA Model Prediction Process. The MRA algorithm was proposed by Pearson K in 1908 [9]. As a classical analytical algorithm, it has been adopted in many fields $[10,11]$, in which many good results have been achieved. However, some studies $[12,13]$ show that due to the poor robustness of the algorithm itself, its prediction accuracy may be reduced due to overfitting when the number of samples is large or the characteristics of the samples are not linear. The multiple regression analysis model in the first stage is used to describe the linear relationship between parking demand and related factors. First, a two-level and ten-category influence factor index system is constructed, with an illustration of the acquisition method of each index. Then, multiple regression analysis is used for fitting, and finally, the residual is output to the next stage. Meanwhile, the possibility of abnormal data in the value of influencing factors is considered. When the predicted outcome of the model is not ideal, it is necessary to eliminate the abnormal data for reprediction (Figure 2).

2.4.2. MRA Model Prediction Algorithm. The MRA model is a quantitative analysis model that examines the relationship between two or more independent variables and dependent variables and is expressed in the form of a mathematical analytical formula on the premise of the linear correlation between independent variables and dependent variables. MRA not only can determine the mathematical analytical formula but also can perform variable analysis according to standardized coefficients.

In this paper, the proportion of car trips, car ownership rate per 1,000 people, location factor index, road network capacity, transit accessibility, building development intensity, commercial area of the building, number of posts in building, parking charging standard, and number of shared parking spots are chosen as independent variables, and the parking demand of commercial-office complex is used as the dependent variable. The determination for RMA is as follows:

$$
P(i)=P_{\mathrm{MRA}}(i)+\varepsilon(i)=A_{0}+A_{1} x_{1}(i)+\cdots+A_{j} x_{j}(i)+\varepsilon(i)(\mathrm{j}=1,2,3, \ldots, 10)
$$

After the parking demand is predicted by MRA, the residual $\varepsilon(i)$ is calculated according to (3). The residual is also used as the dependent variable $\varepsilon(i)$ in Phase II of the BAS-BP algorithm for prediction as follows:

$$
\mathcal{E}(i)=P(i)-P_{\mathrm{MRA}}(i) .
$$

\subsection{Phase II: MRA Residual Correction Algorithm Based on the BAS-BP Algorithm}

2.5.1. BAS-BP Algorithm Operation Process. The phase II algorithm describes the nonlinear relationship between the MRA residual $\varepsilon(i)$ in Phase I and the constructed twolevel and ten-category influence factors. The prediction model combining the MRA model and the other algorithms has been applied in numerous fields. Some scholars combined the artificial fish swarm algorithm (AFSA) with
MRA, which applied the AFSA algorithm to the parameter estimation of the MRA model, and achieved better results than a single MRA model. Some scholars applied the integration of grey correlation analysis and multiple linear regression model to environmental governance and better improved the accuracy of the MRA model. It can be seen that the combined algorithm is suitable for fitting complex solutions with linear and nonlinear relationships. In this paper, the BP neural network, which is commonly used to study nonlinear relationships, is selected to fit the MRA residual.

In 1986, Rumelhart et al. proposed the BP neural network. It has the advantages of simplicity, easy operation, and low computation and can better fit the nonlinear characteristics of variables. However, it suffers the disadvantages of long training time, slow convergence speed, and low accuracy [14]. To overcome the above disadvantages, a variety of models for optimizing the BP 


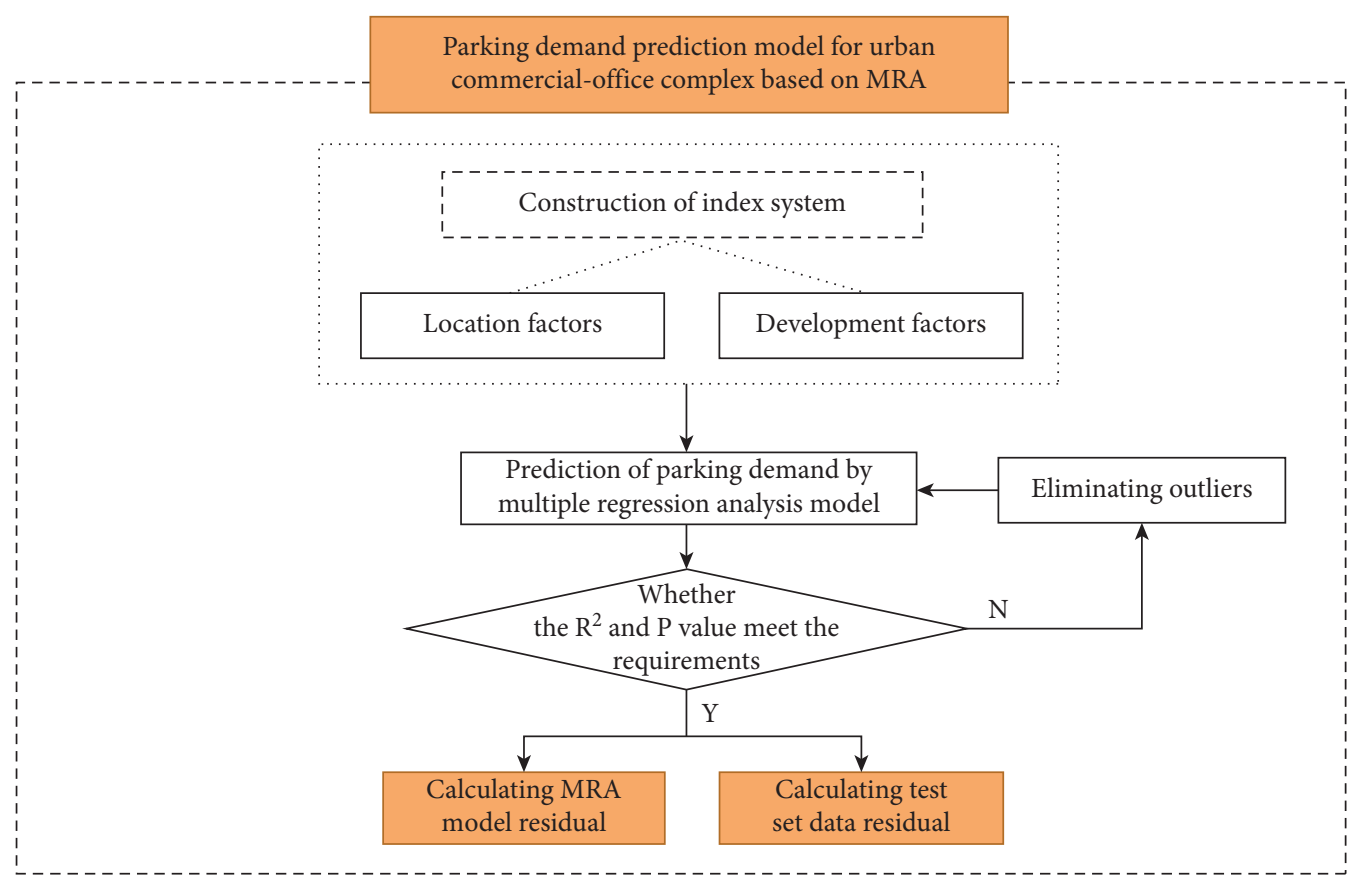

FIGURE 2: MRA model prediction process.

neural network algorithm have been proposed in recent years. The BP neural network with some optimizing algorithms can improve the performance of the neural network, which has been studied and applied in the fields of construction [15], logistics [16], manufacturing [17], and new energy [18]. All the research results show that the optimized BP neural network algorithm performs better than a single BP neural network and has a more accurate and applicable prediction effect.

Meanwhile, among the optimization algorithms, the BAS algorithm has great advantages in dealing with lowdimensional optimization objectives because of its simple principle, fewer parameters, and low computation. It is more suitable for the application scenario of this paper than the conventional optimization algorithms. The BASBP algorithm was first proposed by Wang et al. [19] in 2018. The model was applied to the loss prediction of storm surge disasters and achieved a very small error. $\mathrm{Xu}$ et al. [20] applied the BAS-BP model to predict gas explosion pressure under multiple factors and found that the BAS-BP algorithm had higher prediction accuracy and calculation efficiency. Qian et al. [21] used the BAS-BP model with small error and time cost to predict fuel cost and found that the solution proposed by the model is much better than the solution obtained by traditional models.

Therefore, in this paper, the BAS algorithm is used to find and apply the optimal initial weight and threshold of the BP neural network to the set network to construct the final training model. The model constructed in this way can solve problems of poor stability of the standard BP neural network and easily fall into local optimization, thus improving the accuracy and efficiency of prediction.
In this section, based on the MRA residual mentioned above, the BAS-BP algorithm is used to correct the residual. The operation process of the model is shown in Figure 3.

2.5.2. BAS-BP Algorithm Calculation Process. As mentioned earlier, the BAS-BP algorithm has two stages, namely, optimizing the neural network through the BAS algorithm and predicting the MRA residuals through the optimized BP neural network. The detailed steps for the BAS-BP algorithm are described as follows:

Step 1. Normalize the abovementioned original influence factor data and MRA residuals data by using the min-max standardization method and generate BAS-BP training samples. The standardization formula is as follows:

$$
y_{i}^{*}=\frac{y_{i}-y_{\min }}{y_{\max }-y_{\min }} .
$$

Step 2. Initialize the relevant parameters involved in the BAS algorithm and the BP neural network; suppose that the individual position of the longhorn beetle can be represented by parameters $(T, \theta)$, where $T$ is the initial value of the BP algorithm and $\theta$ is the threshold of the $\mathrm{BP}$ algorithm, and the spatial position of the longhorn beetle is initialized as the initial solution set of the beetle antennae search (BAS) algorithm, saved in $x_{\text {best }}$ and recorded as $s=0$. The spatial dimension $k$ of the BAS algorithm is the total undetermined initial weight and threshold of the BP neural network, expressed as follows:

$$
k=(m+n+1) \times L+1 .
$$




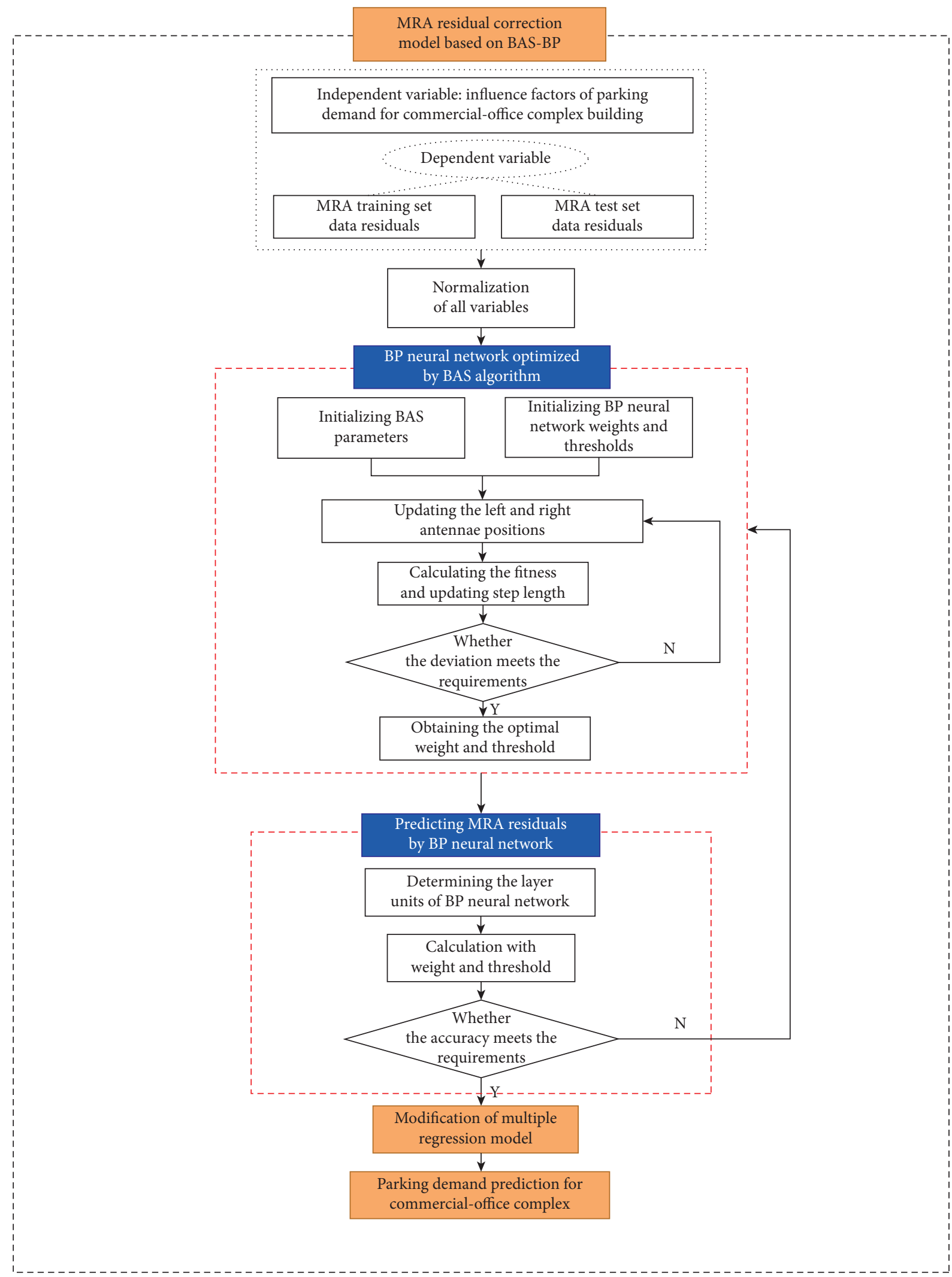

Figure 3: Flow chart of BAS-BP correction residual. 
The moving direction and antenna position update rules of longhorn beetles in each generation are as follows:

$$
\begin{aligned}
& \vec{b}=\frac{\operatorname{rand}(k, 1)}{\|\operatorname{rand}(k, 1)\|}, \\
& x_{l s}=x^{s}-d_{0} * \frac{\vec{b}}{2}, \\
& x_{r s}=x^{s}+d_{0} * \frac{\vec{b}}{2}(s=0,1,2 \ldots \ldots n) .
\end{aligned}
$$

In the BAS algorithm, the location update rule of longhorn beetles in each generation is as follows:

$$
x^{s+1}=x^{s}-\operatorname{step} * \vec{b} * \operatorname{sign}\left(f\left(x_{\mathrm{ls}}\right)-f\left(x_{\mathrm{rs}}\right)\right) .
$$

In the search process, the next forward direction and step length ste $p$ will be determined according to the target fitness perceived by the left and right antennae of the longhorn beetle at the current position. Meanwhile, eta will be reduced continuously to approach the target more accurately. In this process, the update equation of the step length and step length factor of the longhorn beetle is as follows:

$$
\begin{gathered}
\text { step }^{s+1}=\operatorname{step}^{s} * \operatorname{eta}^{s}, \\
\text { eta }^{s+1}=\operatorname{eta}^{s} * 0.95
\end{gathered}
$$

Step 3. Replace $x_{\text {best }}^{s}$ with $x_{\text {best }}^{s+1}$; bring it into the fitness function and judge whether the optimal fitness value meets the set search accuracy $\rho$. If the accuracy requirement is met, stop the iteration and keep the optimal location $x_{\text {best }}^{s}$ of the longhorn beetle and the corresponding $(T, \theta)$ values as the optimal initial value and threshold of BP to predict the residuals of parking demand of complex buildings; otherwise, continue the iteration.

The parameters involved in the BP neural network include mainly the number of neurons in the input layer $m$, the number of neurons in output layer $n$, the number of neurons in hidden layer $L$ and learning rate $\eta$, activation function $f$, each connection weight, and threshold.

Step 4. Take the original parking demand influence factors as the neural network input value and the residuals $\varepsilon(i)$ as the neural network output value, train and predict the MRA residuals with the BP neural network optimized by BAS, and finally output the predicting outcome $\zeta(i)$. Finally, the residuals obtained from BAS-BP prediction are used to modify the MRA model. The modification formula is as follows:

$$
P_{o}(i)=P_{\mathrm{MRA}}(i)+\zeta(i)
$$

\section{Example Analysis}

3.1. Description of Example Problem and Index Calculation. To test the performance of the above algorithms, in this section, the parking demands of 60 commercial-office complexes in Jiangsu Province of China are predicted. The basic data for each complex are shown in Table 3. By using the 10 indices described in the table, a prediction model is established for each complex. The parking demand $P$ is chosen as the dependent variable. The proportion of car trips $x_{1}$, car ownership rate per 1,000 people $x_{2}$, location index $x_{3}$, road network capacity $x_{4}$, transit accessibility index $x_{5}$, commercial area of building $x_{6}$, number of posts in building $x_{7}$, parking charging standard $x_{8}$, number of shared parking spots $x_{9}$, and building development intensity $x_{10}$ are selected as the independent variables. The first 50 groups of data are used as the training set, and the last 10 groups of data are used as the test set.

\subsection{Model Construction and Solution}

3.2.1. MRA Model Operation Process and Result. According to the algorithm idea mentioned above, the solution of the first stage is completed. After the multiple regression analysis of the first 50 groups of data, the correlation coefficient $R^{2}=0.891$, the statistical observation value $F=120.737$, and the $p$ value of the regression analysis model $p=3.4 * 10^{-26}$ can be obtained, indicating that the established multiple regression model can explain $89.1 \%$ of the parking demand of urban commercial-office complexes, and the fitting effect is ordinary, but the significance test statistic $\mathrm{F}$ of the regression formula is large, and the test $p$ is far less than 0.5 , showing that at least one of the regression coefficients is not zero, and the established MRA model is statistically significant.

After the nonstandardized coefficients of each parameter in Table 4 are determined, the function of multiple regression analysis is as follows:

$$
\begin{array}{r}
P=-10.3992+26.84757 x_{1}+0.1291 x_{2}+8.05296 x_{3}-366.024 x_{4}+0.119365 x_{5}+ \\
0.000661 x_{6}-79.5658 x_{7}-0.34333 x_{8}+374.3895 x_{9}+139.6442 x_{10} .
\end{array}
$$

The first 50 groups of data are for back substitution by regression formula (11), and the last 10 groups of data are predicted as the test data.

The residual $\varepsilon_{i}$ is calculated by equation (4) (see Table 5 for some results).
3.2.2. Fitting of Multiple Regression Residuals BAS-BP Algorithm. The operation at this stage is based on the MRA predicted outcomes. According to the algorithm idea described above, the optimal solution found by BAS corresponds to the weight and threshold $(T, \theta)$ of the BP neural 
TABle 3: Summary of basic data of each index.

\begin{tabular}{lccccccccccc}
\hline No. & $x_{1}$ & $x_{2}$ & $x_{3}$ & $x_{4}$ & $x_{5}$ & $x_{6}$ & $x_{7}$ & $x_{8}$ & $x_{9}$ & $x_{10}$ & $p$ \\
\hline 1 & 0.73 & 177 & 12.9 & 1.04 & 2.17 & 8700 & 857 & 1.5 & 76 & 2.1 & 813 \\
2 & 0.68 & 181 & 14 & 0.95 & 1.58 & 6300 & 619 & 1.7 & 85 & 1.5 & 564 \\
3 & 0.69 & 199 & 17.5 & 0.79 & 3.42 & 13600 & 1113 & 1.8 & 202 & 3 & 1340 \\
4 & 0.76 & 156 & 15.8 & 0.73 & 1.38 & 3,950 & 310 & 1.5 & 24 & 1.3 & 461 \\
$\ldots$ & $\ldots$ & $\ldots$ & $\ldots$ & $\ldots$ & $\ldots$ & $\ldots$ & $\ldots$ & $\ldots$ & $\ldots$ & $\ldots$ & $\ldots$ \\
55 & 0.42 & 114 & 0.59 & 602.6 & 478 & 1.01 & 44 & 7.49 & 1.25 & 1.37 & 425 \\
56 & 0.25 & 80 & 0.36 & 258.9 & 272 & 0.59 & 28 & 6.53 & 0.69 & 0.54 \\
57 & 0.28 & 84 & 0.33 & 538.0 & 451 & 0.59 & 85 & 5.71 & 1.40 & 1.23 \\
58 & 0.55 & 94 & 0.44 & 506.1 & 540 & 1.05 & 55 & 7.50 & 1.35 & 1.09 \\
59 & 0.44 & 72 & 0.38 & 103.2 & 176 & 0.82 & 11 & 8.45 & 0.56 & 0.35 \\
60 & 0.36 & 94 & 0.49 & 287.6 & 397 & 0.97 & 28 & 9.71 & 0.98 & 0.88 \\
\hline
\end{tabular}

Note: The above specific values and calculation process are not repeated due to space limitations, and the complete data can be seen in the Appendix.

TABLE 4: MRA model coefficient values.

\begin{tabular}{lr}
\hline Model variables & Nonstandardized coefficient \\
\hline Constant term & -10.3992 \\
$x_{1}$ & 26.84757 \\
$x_{2}$ & 0.1291 \\
$x_{3}$ & 8.05296 \\
$x_{4}$ & -366.024 \\
$x_{5}$ & 0.119365 \\
$x_{6}$ & 0.000661 \\
$x_{7}$ & -79.5658 \\
$x_{8}$ & -0.34333 \\
$x_{9}$ & 374.3895 \\
$x_{10}$ & 139.6442 \\
\hline
\end{tabular}

network. The BP neural network parameters in line with the actual data are determined according to the parameters of the neural network, and the BAS algorithm is used for optimization (Figure 4).

(1) Parameter Initialization of BAS-BP Neural Network. According to the number of parameters in Table 3, set the number of input layers $m=10$, the number of output layers $n=1$, the learning rate of the $\mathrm{BP}$ neural network $\eta=0.1$, and the activation function $f=1 / 1+\exp (-x)$ to calculate the number of layers in the hidden layer, $L$, and take $L=9$, according to the above calculation method.

The maximum number of iterations of BAS is 100 . According to (6), the data dimension $k=(m+n+1) \times L+$ $1=109$ of the BAS is known, and the step length of the BAS algorithm is iterated according to (9).

(2) Variable Normalization of BAS-BP Neural Network. After the independent variables and residuals are normalized through (5), the results are shown in Table 6.

(3) Fitting Results of BAS-BP Algorithm. In this experiment, the comparison between the fitting results of the BP and BAS-BP prediction algorithms is shown in Figure 5. The first 50 groups of data are used as the training set and the last 10 groups of data are test sets. From this figure, the MRA residual curve predicted by the BAS-BP optimized model can be seen to be closer to the real value. At the same time, the MRA residuals are predicted by the conventional BP neural network fall into local optimization, and its predicted outcome is not ideal.

The best fitness curve of the BAS-BP algorithm is shown in Figure 6. The optimal solution can be found after 43 iterations, and the convergence speed is significantly improved in comparison with the convergence speed of the conventional BP algorithm.

Meanwhile, in this paper, we compare the CPU running time, relative mean error, and correlation coefficient $\left(R^{2}\right)$ of the BAS-BP algorithm with those of the conventional BP algorithm to evaluate the superiority of the BAS-BP algorithm. The results are shown in Table 7 .

3.2.3. Predicted Results of MRA-BAS-BP Algorithm. The BAS-BP predicted value of MRA residuals is obtained through the calculation in the first two stages, and the residual predicted value is fed back to the MRA model for reprediction of parking demand. The outcomes are shown in Figure 7.

Meanwhile, in this paper, the author summarizes the error values of the MRA model and MRA-BAS-BP algorithm to compare the superiority of the MRA-BAS-BP algorithm proposed in this paper over the conventional MRA model. The results are shown in Table 8 (in fact, the predicted value of parking demand described in Table 8 is not a strict integer, so the rounding method is adopted to obtain an integer in this paper). Table 8 shows that the mean error of MRA is $7.406 \%$ and that of MRA-BAS-BP is $2.985 \%$. The 
TABLE 5: Statistics of MRA predicted value and residuals.

\begin{tabular}{lcccccccc}
\hline No. & Predicted value & Residual $\varepsilon_{i}$ & No. & Predicted value & Residual $\varepsilon_{i}$ & No. & Predicted value & Residual $\varepsilon_{i}$ \\
\hline 1 & 803.46 & -9.54 & 47 & 395.53 & -2.52 & 54 & 389.01 & -32.16 \\
2 & 489.47 & -74.53 & 48 & 649.23 & -123.38 & 55 & 572.64 & -147.92 \\
3 & 1436.94 & 96.94 & 49 & 289.76 & -74.97 & 56 & 214.24 \\
4 & 489.28 & 28.28 & 50 & 232.13 & -59.34 & 57 & 586.98 & -46.70 \\
5 & 525.78 & 19.78 & 51 & 338.24 & -107.53 & 58 & 488.76 & -85.29 \\
6 & 74.29 & -41.71 & 52 & 257.02 & -62.23 & 59 & 119.78 & -24.56 \\
$\ldots$ & $\ldots$ & $\ldots$ & 53 & 279.35 & -61.79 & 60 & 366.75 & -53.27 \\
\hline
\end{tabular}

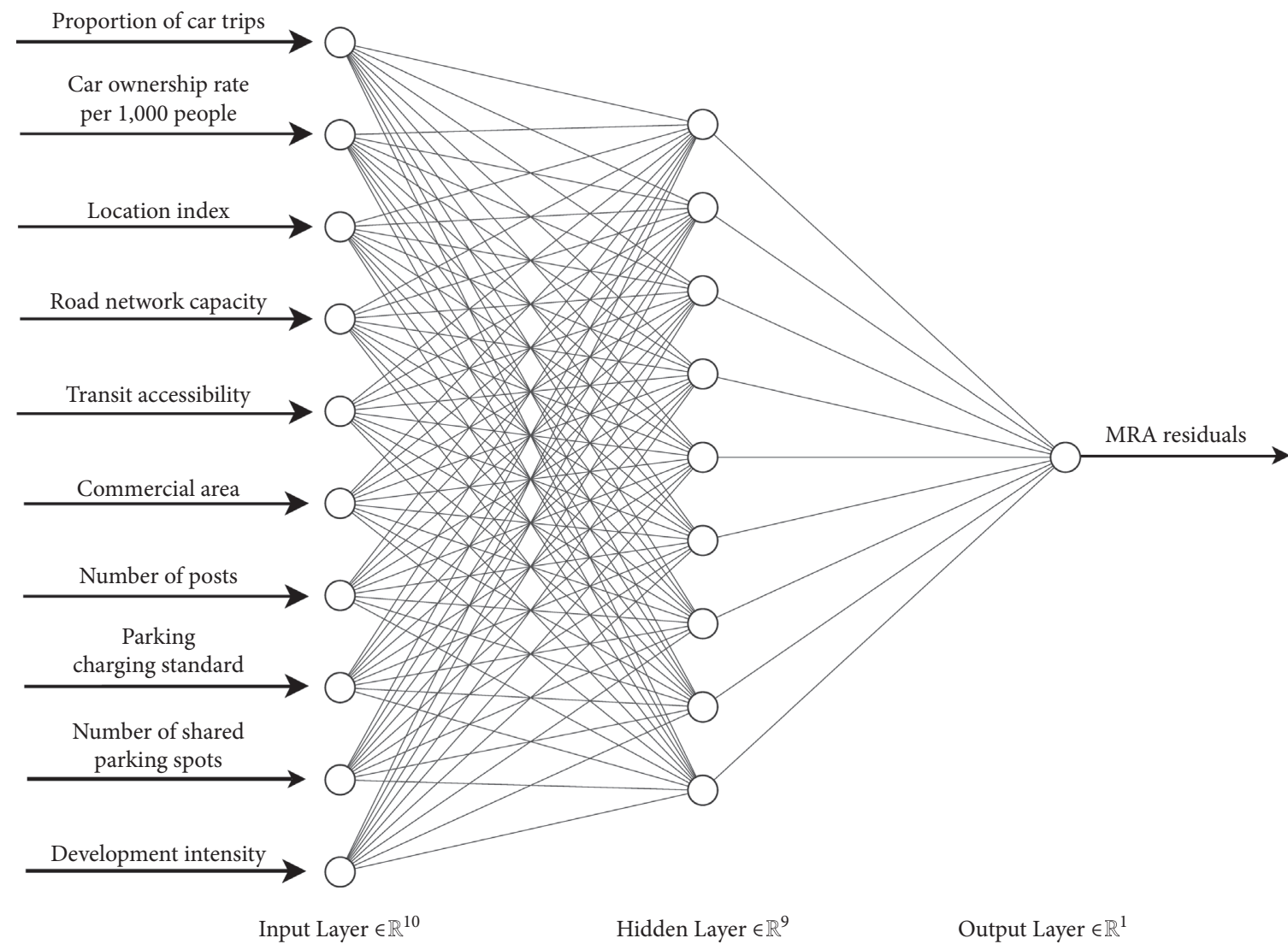

FIGURE 4: Structure of residual prediction of BP neural network.

TABLE 6: Statistics of normalized variable data.

\begin{tabular}{lccccccccccc}
\hline No. & $x_{1}$ & $x_{2}$ & $x_{3}$ & $x_{4}$ & $x_{5}$ & $x_{6}$ & $x_{7}$ & $x_{8}$ & $x_{9}$ & $x_{10}$ \\
\hline 1 & 0.79 & 0.85 & 1.00 & 0.62 & 0.74 & 0.60 & 0.35 & 0.64 & 0.59 & 0.68 & 0.41 \\
2 & 0.71 & 0.88 & 0.88 & 0.43 & 0.51 & 0.73 & 0.40 & 0.73 & 0.39 & 0.46 & 0.48 \\
3 & 0.73 & 1.00 & 0.66 & 1.00 & 1.00 & 0.80 & 1.00 & 1.00 & 1.00 & 1.00 & 0.06 \\
4 & 0.84 & 0.72 & 0.58 & 0.25 & 0.20 & 0.60 & 0.08 & 0.87 & 0.32 & 0.39 & 0.56 \\
$\ldots$ & $\ldots$ & $\ldots$ & $\ldots$ & $\ldots$ & $\ldots$ & $\ldots$ & $\ldots$ & $\ldots$ & $\ldots$ & $\ldots$ & $\ldots$ \\
55 & 0.30 & 0.44 & 0.40 & 0.41 & 0.37 & 0.28 & 0.19 & 0.23 & 0.28 & 0.41 & 0.40 \\
56 & 0.02 & 0.22 & 0.08 & 0.14 & 0.16 & 0.00 & 0.10 & 0.15 & 0.10 & 0.12 \\
57 & 0.08 & 0.24 & 0.05 & 0.36 & 0.34 & -0.01 & 0.40 & 0.09 & 0.33 & 0.36 \\
58 & 0.51 & 0.30 & 0.20 & 0.33 & 0.43 & 0.30 & 0.24 & 0.23 & 0.31 & 0.31 \\
59 & 0.33 & 0.17 & 0.12 & 0.02 & 0.06 & 0.15 & 0.02 & 0.30 & 0.05 & 0.05 \\
60 & 0.21 & 0.31 & 0.26 & 0.16 & 0.28 & 0.25 & 0.10 & 0.40 & 0.19 & 0.45 \\
\hline
\end{tabular}




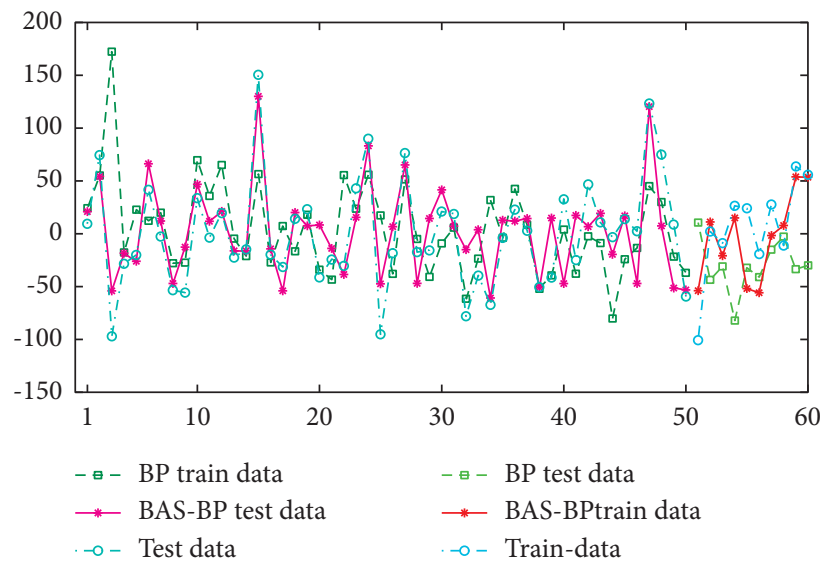

FIgURE 5: Comparison of predicted outcomes of BP and BAS-BP algorithms.

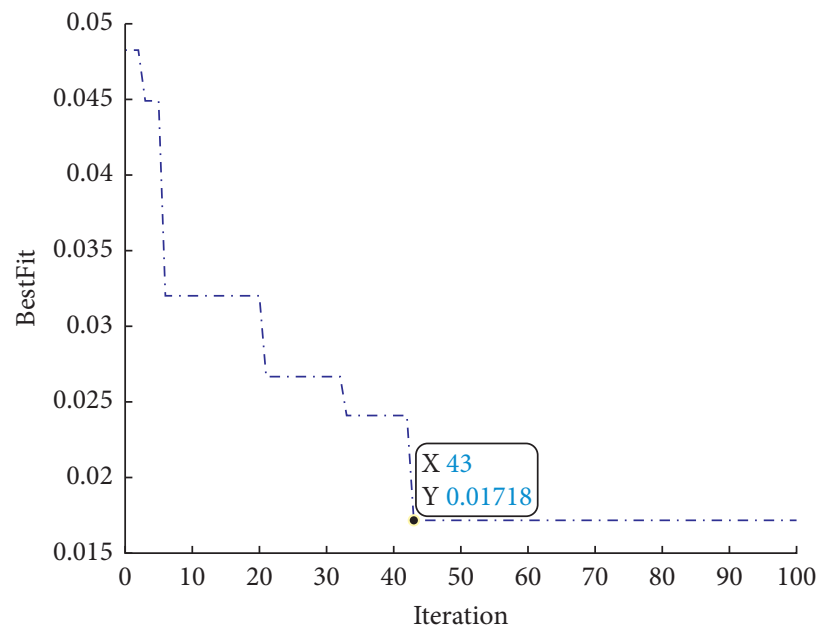

FIgURE 6: Best fitness curve of BAS-BP algorithm.

TABLE 7: Comparison of superiority between BP and BAS-BP algorithms.

\begin{tabular}{lccccc}
\hline \multirow{2}{*}{ Algorithm type } & \multicolumn{2}{c}{ Relative mean error } & \multicolumn{2}{c}{$R^{2}$} & \multicolumn{2}{c}{ CPU running time (s) } \\
& Training set & Test set & Training set & Test set & 0.718 \\
BP neural network & 1.968 & 1.572 & 0.791 & 0.898 & 1.231 \\
BAS-BP algorithm & 1.779 & 0.759 & 0.816 & 0.439 \\
\hline
\end{tabular}

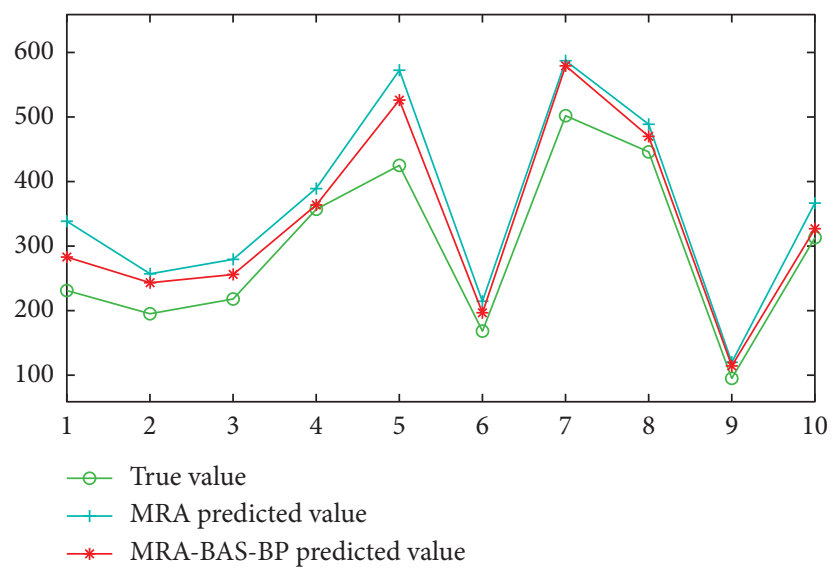

FIgURE 7: Comparison of predicted outcomes of MRA and MRA-BAS-BP algorithms. 
TABLE 8: Comparison of prediction errors between MRA and MRA-BAS-BP algorithms.

\begin{tabular}{|c|c|c|c|c|c|}
\hline \multirow{2}{*}{ No. } & \multirow{2}{*}{ Actual value } & \multicolumn{2}{|c|}{ MRA } & \multicolumn{2}{|c|}{ MRA-BAS-BP } \\
\hline & & Predicted value & Relative error (\%) & Predicted value & Relative error (\%) \\
\hline 51 & 231 & 338 & 46.611 & 283 & 22.599 \\
\hline 52 & 195 & 257 & 31.946 & 243 & 24.641 \\
\hline 53 & 218 & 279 & 28.399 & 256 & 17.699 \\
\hline 54 & 357 & 389 & 9.012 & 363 & 1.841 \\
\hline 55 & 425 & 573 & 34.826 & 526 & 23.875 \\
\hline 56 & 168 & 214 & 27.874 & 197 & 17.376 \\
\hline 57 & 502 & 587 & 17.000 & 579 & 15.480 \\
\hline 58 & 446 & 489 & 9.600 & 470 & 5.390 \\
\hline 59 & 95 & 120 & 25.792 & 114 & 19.781 \\
\hline 60 & 313 & 367 & 16.994 & 327 & 4.266 \\
\hline Mean error & & \multicolumn{2}{|c|}{$7.406 \%$} & \multicolumn{2}{|c|}{$2.985 \%$} \\
\hline
\end{tabular}

predicted outcomes are good, and the prediction accuracy is greatly improved compared with the conventional MRA model, which verifies that the proposed model is scientific and accurate and proposes a reliable prediction method for the parking demand of urban commercial-office complexes.

\section{Conclusions}

The parking demand prediction for urban commercial-office complexes is one of the most important portions of urban parking planning. Based on the studies of the prediction of parking demand of the existing urban commercial-office complexes, in this paper, the author constructs a two-level and ten-category influence factor index system and carries out regression analysis and puts forward a two-stage prediction method of parking demand based on MRA-BAS-BP, which is verified by with practical examples. The main conclusions of this paper are as follows: (1) the index system proposed in this paper can comprehensively describe the parking demand characteristics of urban commercial-office complex buildings; (2) the BAS-BP algorithm used in this paper has higher accuracy and faster running speed than the conventional BP neural network; and (3) the results of numerical examples show that the MRA-BAS-BP algorithm proposed in this paper can effectively improve the prediction accuracy compared with the original single MRA model, contains certain feasibility, and can provide more accurate data support for urban parking planning.

\section{Data Availability}

The data used to support the findings of this study are included within the supplementary information file.

\section{Conflicts of Interest}

The authors declare that they have no conflicts of interest.

\section{Supplementary Materials}

The data in the supplementary materials are all the contents of the charts in the paper, and the table numbers correspond to each other one by one. (Supplementary Materials)

\section{References}

[1] T. Cheng, M. Tai, and Z. Ma, "The model of parking demand forecast for the urban CCD," Energy Procedia, vol. 16, pp. 1393-1400, 2012.

[2] J. F. Yu, X. L. Gong, and X. J. Zhang, "Parking demand forecast method of big city and its application," Applied Mechanics and Materials, vol. 587-589, pp. 1753-1756, 2014.

[3] Y. Liu, C. Liu, and X. Luo, "Spatiotemporal deep-learning networks for shared-parking demand prediction," Journal of Transportation Engineering, Part A: Systems, vol. 147, no. 6, Article ID 04021026, 2021.

[4] S. Gai, X. Zeng, and T. Yuan, "Parking volume forecast of railway station garages based on passenger behaviour analysis using the LSTM network," Journal of Advanced Transportation, vol. 2021, Article ID 6688609, 14 pages, 2021.

[5] J. F Mata, U Bozlar, J. P. Mugler, G. W. Miller, S. S. Berr, and K. D. Hagspiel, "Time-resolved and high-resolution MRA in a rabbit model of pulmonary embolism at $7 \mathrm{~T}$ : preliminary results," Magnetic Resonance Imaging, vol. 28, no. 1, pp. 139-145, 2010.

[6] J. Xiong, "Method for constructing the model of parking demand forecasting based on time interval statistical analysis," Design Engineering, vol. 1, pp. 457-467, 2020.

[7] L. marchan, A Generalized Concept - Time and Space Consumption of Cities, Urban Transportation Research References (Episode I) [M], Tianjin transportation comprehensive research group, Tianjin, 1986.

[8] H. Qin, Q. Xiao, H. Guan, and X. Pan, Analysis on the Parking Demand of the Commercial Buildings Considering the Public Transport Accessibility, Commercial Buildings in Beijing as an Example, Nature and Science, Beijing, China, 2010.

[9] K. Pearson, "Cousin marriages," BMJ, vol. 1, no. 2472, p. 1207, 1908.

[10] H. B. Dave, D. Singh, and H. O. Bansal, "Multiple linear regression-based impact analysis of impedance network design on life expectancy of DC-link capacitor in q-ZSI fed motor drive," Engineering Science and Technology, an International Journal, vol. 24, no. 1, pp. 171-182, 2021.

[11] S. Kwak, J. Kim, H. Ding et al., "Using multiple regression analysis to predict directionally solidified TiAl mechanical property," Journal of Materials Science \& Technology, vol. 104, 2021.

[12] S. Rath, A. Tripathy, and A. R. Tripathy, "Prediction of new active cases of coronavirus disease (COVID-19) pandemic using multiple linear regression model," Diabetes \& Metabolic 
Syndrome: Clinical Research Reviews, vol. 14, no. 5, pp. 1467-1474, 2020.

[13] A. Ferreira Schon, N. Apoena Castro, A. dos Santos Barros et al., "Multiple linear regression approach to predict tensile properties of Sn-Ag-Cu (SAC) alloys," Materials Letters, vol. 304, Article ID 130587, 2021.

[14] D. E. Rumelhart, G. E. Hinton, and R. J. Williams, "Learning representations by back-propagating errors," Nature, vol. 323, no. 6088, pp. 533-536, 1986.

[15] Y. Chang, J. Yue, R. Guo, W. Liu, and L. Li, "Penetration quality prediction of asymmetrical fillet root welding based on optimized BP neural network," Journal of Manufacturing Processes, vol. 50, pp. 247-254, 2020.

[16] J. Feng, B. Yuan, X. Li, D. Tian, and W. Mu, "Evaluation on risks of sustainable supply chain based on optimized BP neural networks in fresh grape industry," Computers and Electronics in Agriculture, vol. 183, Article ID 105988, 2021.

[17] H. Cao, L. Liu, B. Wu, Y. Gao, and D. Qu, "Process optimization of high-speed dry milling UD-CF/PEEK laminates using GA-BP neural network," Composites Part B: Engineering, vol. 221, Article ID 109034, 2021.

[18] Z. Li, Y. Qin, S. Hou, R. Zhang, and H. Sun, "Renewable energy system based on IFOA-BP neural network load forecast," Energy Reports, vol. 6, no. Supplement 9, pp. 1585-1590, 2020.

[19] T. Wang and Q. Liu, "Storm surge disaster loss prediction based on BAS-BP model," Marine Environmental Science, vol. 37, no. 3, pp. 457-463, 2018.

[20] Y. Xu, Y. Huang, and G. Ma, "A beetle antennae search improved BP neural network model for predicting multifactor-based gas explosion pressures," Journal of Loss Prevention in the Process Industries, vol. 65, Article ID 104117, 2020.

[21] J. Qian, P. Wang, C. Pu, and G. Chen, "Joint application of multi-object beetle antennae search algorithm and BAS-BP fuel cost forecast network on optimal active power dispatch problems," Knowledge-Based Systems, vol. 226, no. 17, Article ID 107149, 2021. 